\title{
INTERPROFESSIONAL COLLABORATION ON MENTAL HEALTH: A SCOPING REVIEW
}

\author{
Arista Kusuma Wardani'1), Sulistiyaningsih²) \\ ${ }^{1)}$ Master of Midwifery Program, Universitas 'Aisyiyah Yogyakarta \\ 2)Faculty of Public Health, Universitas 'Aisyiyah Yogyakarta
}

\begin{abstract}
Background: The increasing prevalence rate of mental illness due to demographic changes became the burden of disease in primary health care. Effective interprofessional collaboration strategies are required to improve professional welfare and quality of care. Interdisciplinary teamwork plays an important role in the treatment of chronic care, including mental illness. This scoping review aimed to investigate the benefit and barrier of interprofessional collaboration approach to mental health care.

Subjects and Method: A scoping review method was conducted in eight stages including (1) Identification of study problems; (2) Determining priority problem and study question; (3) Determining framework; (4) Literature searching; (5) Article selection; (6) Critical appraisal; (7) Data extraction; and (8) Mapping. The search included PubMed, ScienceDirect, and Willey Online library databases. The inclusion criteria were English-language, full-text, and free access articles published between 2010 and 2020. The data were reported by the PRISMA flow chart.

Results: A total of 316 articles obtained from the search databases, in which 263 articles unmet the inclusion criteria and 53 duplicates were excluded. Based on the selected seven articles, one article from a developed country (Malaysia), and six articles from developing countries (Australia, Canada, Belgium, Norway) with quantitative (cross-sectional, surveillance) and qualitative study designs. The reviewed findings were benefit and barrier of interprofessional collaboration on mental health. Benefits included improve quality of care, increase job satisfaction, improve patient health status, increase staff satisfaction, increase performance motivation among employees, as well as shorter duration of treatment and lower cost. Barriers included hierarchy culture, lack of resources, lack of time, poor communication, and inadequate training.
\end{abstract}

Conclusion: Interprofessional teamwork and collaboration have been considered an essential solution for effective mental health care.

Keywords: interprofessional collaboration, benefit, barrier, mental health

\section{Correspondence:}

Arista Kusuma Wardani. Universitas 'Aisyiyah Yogyakarta. Jl. Siliwangi (Ring Road Barat) No. 63 Mlangi, Nogotirto, Gamping, Sleman, Yogyakarta, 55292. Email: wardanikusuma1313@gmail.com. Mobile: +6281805204773

The $7^{\text {th }}$ International Conference on Public Health Solo, Indonesia, November 18-19, 2020 341 https://doi.org/10.26911/the7thicph.04.26 